\title{
A utilização de glicerina em dietas para bovinos altera a microbiota ruminal
}

[The use of glycerin in cattle diets alter the rumen microflora]

\author{
V.R. Fávaro ${ }^{l}$, J.M.B. Ezequiel ${ }^{2}$, A.P. D'Aurea ${ }^{l}$, J.B.D. Sancanari ${ }^{2}$, A.C. Homem Júnior ${ }^{l}$, \\ E.H.C.B. van Cleef $^{1}$, V.C. Santos ${ }^{2}$ \\ ${ }^{1}$ Aluno de pós-graduação - Universidade Estadual Paulista - Unesp - Jaboticabal, SP \\ ${ }^{2}$ Universidade Estadual Paulista - Unesp - Jaboticabal, SP
}

\begin{abstract}
RESUMO
Objetivou-se com este estudo avaliar a produção e composição das bactérias e protozoários ruminais de bovinos alimentados com glicerina. Cinco bovinos machos, providos de cânulas ruminais, foram distribuídos em delineamento experimental quadrado latino ( 5 x 5). As dietas foram formuladas com a inclusão de 0, 5, 10, 15 e 20\% de glicerina na matéria seca (MS). Foram colhidas amostras de conteúdo ruminal nos tempos $0,2,5$ e 8 horas após a alimentação e, em seguida, separaram-se as frações sólida e líquida para determinação das bactérias líquido-associadas (BLA), protozoários líquido-associados (PLA) e bactérias sólido-aderidas (BSA). Com o acréscimo da concentração de glicerina na dieta, houve redução linear na produção de MS das BLA e PLA $(\mathrm{P}<0,05)$. No tratamento sem inclusão de glicerina, as quantidades de $\mathrm{MS}$ foram de 1.048,5 e 2.199,5 mg/L para BLA e PLA, respectivamente, enquanto no tratamento com $20 \%$ de glicerina foram, respectivamente, 756,9 e $1.619,9 \mathrm{mg} / \mathrm{L}$ para BLA e PLA. Além disso, houve redução nos teores de matéria orgânica (MO) e aumento linear do teor de nitrogênio (N) das BLA com o aumento da concentração de glicerina na dieta. A composição dos protozoários não foi alterada em função dos tratamentos (em média 47,3\% MO e 7,2\% N). A produção das BSA não foi alterada $(\mathrm{P}>0,05)$ com o incremento da glicerina na dieta, e os valores médios para as quantidades de MS, MO e $\mathrm{N}$ foram, respectivamente, 3.131,0; $2.463,1$ e $294,2 \mathrm{mg} / \mathrm{kg}$. Houve aumento linear no teor de $\mathrm{N}$ das BSA de 10,8 para $11,3 \%$ nos tratamentos com 0 e $20 \%$ de glicerina, respectivamente. Não foi verificado efeito do tempo de colheita para as BSA, ao passo que, para as BLA, ocorreu redução na produção de MO e nos teores de MO e N. A utilização de altas concentrações de glicerina na dieta de bovinos necessita de maiores estudos, pois há alteração da produção e composição dos microrganismos ruminais.
\end{abstract}

Palavras-chave: biodiesel, microrganismos, rúmen, subproduto

\begin{abstract}
The aim of this study was to evaluate the production and composition of ruminal bacteria and protozoa in cattle fed with glycerin. Five steers, provided with ruminal cannulas, were distributed in a latin square design (5 x 5). Diets were formulated to contain 0, 5, 10, 15, or $20 \%$ of glycerin on dry matter (DM) basis. Rumen content samples were collected at 0, 2, 5 and 8 hours after feeding that were separated in solid and liquid phases to determine the amount of liquid associated bacteria (LAB), liquid associated protozoa (LAP) and particle-associated bacteria $(P A B)$. With the increase of glycerin concentration in the diet there was a linear reduction in $D M$ production of $L A B$ and $L A P(P<0.05)$. In the treatment without glycerin the amount of DM was 1048.5 and $2199.5 \mathrm{mg} / \mathrm{L}$ for LAB and LAP respectively, while in the treatment with $20 \%$ of glycerin it was respectively 756.9 and $1619.9 \mathrm{mg} / \mathrm{L}$ for LAB and LAP. Furthermore, there was a reduction in the content of organic matter $(O M)$ and a linear increase in nitrogen $(N)$ of $L A B$ with increasing concentration of glycerin in the diet. The composition of protozoa was not altered by the treatments (average $47.3 \%$ OM and $7.2 \% \mathrm{~N}$ ). The production of PAB was not affected $(P>0.05)$ by the increasing dietary glycerin and mean values for the quantities of DM, OM and $N$
\end{abstract}

Recebido em 19 de março de 2013

Aceito em 11 de fevereiro de 2014

E-mail: vanessa_favaro@yahoo.com.br 
were respectively 3131.0, 2463.1 and $294.2 \mathrm{mg} / \mathrm{kg}$. There was a linear increase in $\mathrm{N}$ content of PAB from 10.8 to $11.3 \%$ for treatments with 0 and $20 \%$ of glycerin respectively. There was no effect on harvest time for PAB, while for LAB there was reduction in OM production and in OM and $N$ contents. The use of high concentrations of glycerin in the cattle diet requires further study, because there are changes in the production and composition of rumen microorganisms.

Keywords: biodiesel, byproduct, microorganisms, rumen

\section{INTRODUÇÃO}

A rápida expansão da indústria do biodiesel a partir de 2008, em que o governo federal estabeleceu a obrigatoriedade de adição de $2 \%$ de biodiesel ao óleo diesel (Agência..., 2012), resultou em significativo aumento na produção de glicerina. A dificuldade de acomodação do excedente desta se agrava porque a glicerina resultante da produção de biodiesel tem características diferentes da utilizada na indústria de higiene e cosmética.

Uma alternativa é o emprego desse subproduto na alimentação animal, podendo ser acrescentado na ração como fonte energética. É crescente o interesse de utilização da glicerina na alimentação animal devido ao aumento na disponibilidade e preços favoráveis. Parcela significativa das pesquisas sobre glicerina na alimentação de ruminantes está relacionada ao desempenho animal e qualidade de carne (Pyatt et al., 2007; Mach et al., 2009; Parsons et al., 2009; Gunn et al., 2010; Gomes et al., 2011). Portanto, o efeito do glicerol e o padrão de fermentação sobre os microrganismos ruminais não estão completamente elucidados.

Krehbiel (2008) relatou que cerca de $13 \%$ do glicerol que chega ao rúmen desaparece por passagem com a digesta, $43 \%$ por absorção pela parede do rúmen e $44 \%$ por fermentação, sendo o principal produto da fermentação o propionato (Lee et al., 2011). Contudo, em avaliação in vitro, Paggi et al. (2004) relataram que a atividade celulolítica do rúmen foi reduzida quando a concentração de glicerol passou de 50 para 300mM; adicionalmente, Abo El-Nor et al. (2010) verificaram redução na concentração do DNA das bactérias Butyrivibrio fibrisolvens e Selenomonas ruminantium ao adicionar glicerina na dieta em concentrações superiores a $72 \mathrm{~g}$ de glicerol $/ \mathrm{kg}$ de matéria seca.

A otimização da fermentação ruminal, juntamente com a maximização da eficiência de síntese de proteína microbiana, tem sido o foco de várias pesquisas, sendo o aumento na utilização da energia no rúmen, a maximização do uso do nitrogênio pelas bactérias ruminais e a redução das perdas por metano e amônia alguns objetivos dos nutricionistas para aumentar com eficiência o desempenho animal (Eugène et al., 2004). Para tanto é necessário o estudo da população de microrganismos presentes no ambiente ruminal e os fatores que resultam em modificações na sua qualidade e funcionalidade.

Objetivou-se com este trabalho avaliar a utilização da glicerina obtida do processo de produção do biodiesel sobre a quantificação e composição das bactérias e protozoários líquido associados e bactérias sólido aderidas do rúmen de bovinos.

\section{MATERIAL E MÉTODOS}

Este trabalho foi desenvolvido na Faculdade de Ciências Agrárias e Veterinárias - FCAV/Unesp, campus de Jaboticabal, conduzido de acordo com as normas éticas e aprovado pela Comissão de Ética no Uso de Animais da Unesp/Jaboticabal (número do protocolo 022811/10).

Foram utilizados cinco bovinos mestiços, castrados, com idade aproximada de dois anos (peso inicial de $500 \pm 50 \mathrm{~kg}$ ), providos de cânulas permanentes no rúmen. Os animais ficaram alojados em baias individuais com livre acesso a bebedouros e cochos. Além disso, foi mantido manejo higiênico/sanitário rigoroso dos animais, sendo as baias e bebedouros higienizados diariamente. As dietas foram formuladas segundo o NRC (National..., 1996) para serem isonitrogenadas e isoenergéticas, com cinco concentrações de glicerina $(0,5,10,15$ e $20 \%$ da MS), mantendo a relação volumoso:concentrado de 40:60 (Tab. 1). A glicerina foi obtida do óleo de soja e apresentou $83 \%$ de glicerol, $11 \%$ de água, $6 \%$ de sais (dos quais $99 \%$ eram $\mathrm{NaCl}$ ) e $0,01 \%$ de metanol (análises realizadas pela Caramuru Alimentos Ltda.). 
Os animais foram alimentados duas vezes ao dia, às $08 \mathrm{~h}$ e $16 \mathrm{~h}$ e receberam água limpa à vontade. Para o fornecimento da ração, diariamente a glicerina era pesada separadamente, misturada primeiramente ao concentrado e depois à silagem no momento da alimentação. $\mathrm{O}$ período experimental teve duração de 90 dias e foi composto de cinco períodos de 18 dias, sendo os 14 primeiros para adaptação dos animais às dietas e os últimos quatro para coleta de dados.

Foram colhidas manualmente amostras de conteúdo ruminal $(3 \mathrm{~kg})$ de cada animal, nos tempos $0,2,5$ e 8 horas após a primeira alimentação, procurando amostrar todas as partes do rúmen. Para separar a fase líquida da fase sólida, o conteúdo ruminal foi inicialmente filtrado em filtro de náilon, com porosidade de $100 \mu \mathrm{m}$, para posterior separação e quantificação de bactérias líquido-associadas (BLA), protozoários líquido-associados (PLA) e bactérias sólido-aderidas (BSA) de acordo com metodologia de Martin et al. (1994). As amostras foram congeladas a $-18^{\circ} \mathrm{C}$ e, posteriormente, analisadas.

Tabela 1. Composição percentual e nutricional das dietas experimentais

\begin{tabular}{|c|c|c|c|c|c|}
\hline \multirow[b]{2}{*}{ Item } & \multicolumn{5}{|c|}{ Glicerina (\%) } \\
\hline & 0 & 5 & 10 & 15 & 20 \\
\hline \multicolumn{6}{|l|}{ Ingredientes (\% da MS) } \\
\hline Silagem de milho & 40 & 40 & 40 & 40 & 40 \\
\hline Milho moído & 39,2 & 33,0 & 27,3 & 21,9 & 15,6 \\
\hline Casca de soja & 7,3 & 8,1 & 8,5 & 8,7 & 7,9 \\
\hline Farelo de girassol & 12,5 & 12,9 & 13,2 & 13,4 & 15,5 \\
\hline Suplemento mineral ${ }^{1}$ & 0,5 & 0,5 & 0,5 & 0,5 & 0,5 \\
\hline Sal comum & 0,5 & 0,5 & 0,5 & 0,5 & 0,5 \\
\hline Glicerina & 0 & 5 & 10 & 15 & 20 \\
\hline \multicolumn{6}{|l|}{ Nutrientes (\% da MS) } \\
\hline Proteína bruta & 12,4 & 12,3 & 12,1 & 12,0 & 11,9 \\
\hline Fibra em detergente neutro & 33,6 & 33,5 & 32,8 & 32,7 & 32,5 \\
\hline Extrato etéreo & 4,6 & 4,3 & 3,9 & 3,5 & 3,1 \\
\hline Energia metabolizável (Mcal/kg) & 2,6 & 2,6 & 2,6 & 2,6 & 2,6 \\
\hline
\end{tabular}

${ }^{1}$ Suplemento Mineral para Bovinos, níveis de garantia por 1.000g do produto: Fósforo 40g, Cálcio 80g, Sódio 195g, Cloro 300g, Magnésio 5g, Enxofre 26g, Zinco $2.000 \mathrm{mg}$, Cobre $1.000 \mathrm{mg}$, Manganês $500 \mathrm{mg}$, Cobalto $100 \mathrm{mg}$, Iodo $100 \mathrm{mg}$, Selênio $5 \mathrm{mg}$, Flúor (máx.) $400 \mathrm{mg}$, veículo q.s.p. $1.000 \mathrm{~g}$.

Para a identificação da fase líquida, o líquido ruminal (1L) foi diluído com igual volume de solução salina (Coleman, 1978), pré-aquecida a $39^{\circ} \mathrm{C}$. O líquido ruminal juntamente com a solução salina foram incubados por 30 a 60 minutos a $39^{\circ} \mathrm{C}$. Nos últimos cinco minutos de incubação, foi adicionada glicose $(1 \mathrm{~g} / \mathrm{L})$, para separar os protozoários do restante do conteúdo ruminal e otimizar a floculação. O pélete de protozoário foi recuperado por centrifugação do fluido clarificado, a 1.000 x g, por 10 minutos, à temperatura ambiente. Posteriormente, esse pélete foi lavado com solução salina em filtro de náilon, com porosidade de $20 \mu \mathrm{m}$ ( 1 litro a $39^{\circ} \mathrm{C}$ ), para minimizar a contaminação por bactérias e resíduos de alimento. As BLA foram obtidas pela centrifugação do fluido sobrenadante livre de protozoário a $15.000 \mathrm{x} \mathrm{g}$, por 20 minutos a $4^{\circ} \mathrm{C}$.
A fase sólida foi identificada utilizando-se $200 \mathrm{~g}$ de amostra sólida ruminal, que foi lavada e agitada manualmente, por cinco minutos, em um frasco com solução salina, pré-aquecida a $39^{\circ} \mathrm{C}$ (1g de material fresco/4mL de solução), para remover a população não aderente associada à fase sólida. Após esse processo, foi realizada uma filtragem em filtro de náilon de $100 \mu \mathrm{m}$. O filtrado foi centrifugado a $1.000 \mathrm{x} \mathrm{g}$, por 10 minutos, à temperatura ambiente, para recuperar o pélete de pequenas partículas de sólido que estavam associadas às grandes partículas que ficaram retidas no filtro. As partículas grandes e pequenas foram combinadas e suspensas em solução salina ( $1 \mathrm{~g}$ de sólido/4mL) pré-resfriada a $4^{\circ} \mathrm{C}$, e posteriormente homogeneizadas três vezes por um minuto no vórtex, em velocidade alta. 
Posteriormente, foram processadas por cinco minutos em "Stomacher ${ }^{\circledR} 400$ circulator". Esse processo mecânico teve como objetivo separar a bactéria associada e algum fungo ou protozoário aderido às partículas, através da homogeneização por combinação de forças mecânicas, esmagando e agitando o material. O homogeneizado foi filtrado em um filtro de náilon com porosidade de $100 \mu \mathrm{m}$, sendo esse processo realizado duas vezes. Os filtrados que continham a população aderente foram agrupados e centrifugados a $1.000 \times$ g por 10 minutos, a $4^{\circ} \mathrm{C}$, para descartar o resíduo de alimento. A fração sobrenadante foi centrifugada a $27.000 \mathrm{x}$ g por 30 minutos, a $4^{\circ} \mathrm{C}$. $\mathrm{O}$ sedimento resultante correspondeu às BSA. Em seguida as amostras foram liofilizadas e analisadas quanto aos teores de nitrogênio (N), matéria seca (MS) e matéria mineral (MM), estimando-se os teores de matéria orgânica (MO), segundo AOAC (Official..., 1995).

O delineamento experimental foi o quadrado latino $5 \mathrm{x} 5$. Os dados foram analisados utilizando-se o procedimento MIXED do SAS (Statistical..., 2003), sendo o fator tempo de colheita considerado como medidas repetidas no tempo conforme o modelo estatístico: $Y=\mu+A_{i}$ $+P_{j}+D_{k}+T_{1}+D_{k} \times T_{1}+e_{i j k l}$, em que $\mu=$ média geral; $A_{i}=$ efeito aleatório do animal ( $i=1$ a 5$)$; $\mathrm{P}_{\mathrm{j}}=$ efeito aleatório do período $(\mathrm{j}=1$ a 5$) ; \mathrm{D}_{\mathrm{k}}=$ efeito fixo da dieta $(\mathrm{k}=1$ a 5$) ; \mathrm{H}_{1}=$ efeito fixo do tempo de colheita $(\mathrm{l}=1 \mathrm{a} 4) ; \mathrm{D}_{\mathrm{k}} \times \mathrm{H}_{\mathrm{l}}=$ interação entre dieta e tempo de colheita; e $\mathrm{e}_{\mathrm{ijkl}}=$ erro residual. Para os fatores tratamento e tempo de colheita realizaram-se contrastes ortogonais para verificar efeitos linear, quadrático e cúbico da inclusão de glicerina, ao nível de significância de 0,05 .

\section{RESULTADOS E DISCUSSÃO}

Não foram observados efeitos da interação tratamento $\mathrm{x}$ tempo de colheita $(\mathrm{P}>0,05)$ para a produção e composição das bactérias líquidoassociadas (BLA), protozoários líquidoassociados (PLA) e bactérias sólido-aderidas (BSA). Portanto, foram considerados apenas os efeitos dos fatores principais.

Houve redução nas produções de MS e MO das BLA com o incremento da glicerina na dieta (Tab. 2). No tratamento sem adição de glicerina, as quantidades de MS e MO (mg/L) foram, respectivamente, 27,8 e $32,2 \%$ superiores ao tratamento com $20 \%$ de glicerina. Além disso, verificou-se redução linear no teor de MO e aumento linear do teor de $\mathrm{N}$ com o acréscimo da concentração de glicerina na dieta $(\mathrm{P}<0,05)$.

Os teores médios de MO (\%MS) e N (\%MO) das frações bacterianas associadas ao líquido ruminal obtidas neste trabalho foram 57,0 e $10,2 \%$, respectivamente. Homem Junior et al. (2010) constataram valores médios de MO de $81,1 \%$ e $11,2 \%$ de $\mathrm{N}$ para bactérias do fluido ruminal, e Ezequiel et al. (2002) relataram teores de $\mathrm{MO}$ de $81,6 \%$ e $6,7 \%$ de $\mathrm{N}$ para as bactérias líquidoassociadas. Pode-se verificar que os teores de MO encontrados por esses autores foram superiores aos obtidos neste trabalho. No entanto, Martin et al. (1994) relataram teores de MO para bactérias da fase líquida na faixa de 60,3 a 64,7\%, e Mendes et al. (2006) encontraram valores médios de MO de 57,0\%, que são mais próximos aos valores obtidos neste trabalho.

Os teores de MO foram baixos, possivelmente pela adição de solução salina durante o processo de separação das frações BLA, PLA e BSA, acarretando em aumento no valor de matéria mineral das amostras. Essa hipótese também foi apontada por Mendes et al. (2006) como causa da grande variação dos teores de MO encontrados na literatura. Segundo Martin et al. (1994), a matéria mineral contida nas amostras das frações isoladas é função da concentração da solução salina utilizada e do número de lavagens em solução salina a que a amostra foi submetida.

Pesquisas preliminares indicam que a glicerina afeta o crescimento de algumas espécies bacterianas ruminais. Abo El-Nor et al. (2010) avaliaram a substituição do milho por glicerina nas concentrações $0,36,72$, e $108 \mathrm{~g} / \mathrm{kg}$ de glicerina na matéria seca da dieta de vacas da raça Holandesa sobre a fermentação ruminal e observaram redução na concentração de DNA das bactérias Butyrivibrio fibrosolvens e Selenomonas ruminantium com o aumento na concentração de glicerina da dieta. Entretanto, o mecanismo não está elucidado, pois a sensibilidade dos microrganismos pode variar de acordo com o nível de inclusão de glicerina na dieta. 
Tabela 2. Produção e composição de bactérias líquido-associadas do rúmen de bovinos em função dos tratamentos

\begin{tabular}{|c|c|c|c|c|c|c|c|c|c|}
\hline \multirow{2}{*}{ Item } & \multicolumn{5}{|c|}{ Glicerina (\%) } & \multirow[b]{2}{*}{$\mathrm{EPM}^{1}$} & \multicolumn{3}{|c|}{ Valores de $\mathrm{P}^{2}$} \\
\hline & 0 & 5 & 10 & 15 & 20 & & $\mathrm{~L}$ & $\mathrm{Q}$ & $\mathrm{C}$ \\
\hline \multicolumn{10}{|c|}{ Matéria seca } \\
\hline $\mathrm{mg} / \mathrm{L}^{3}$ & 1048,5 & 870,5 & 875,5 & 933,1 & 756,9 & 24,4 & 0,004 & 0,755 & 0,016 \\
\hline \multicolumn{10}{|c|}{ Matéria orgânica } \\
\hline$\% \mathrm{MS}$ & 59,6 & 57,6 & 56,3 & 55,8 & 55,6 & 0,5 & 0,004 & 0,207 & 0,925 \\
\hline $\mathrm{mg} / \mathrm{L}^{4}$ & 626,5 & 503,7 & 498,3 & 522,6 & 424,6 & 16,3 & 0,002 & 0,510 & 0,032 \\
\hline \multicolumn{10}{|c|}{ Nitrogênio } \\
\hline$\% \mathrm{MO}$ & 9,5 & 10,0 & 10,2 & 10,4 & 10,9 & 0,1 & 0,017 & 0,913 & 0,614 \\
\hline $\mathrm{mg} / \mathrm{L}^{5}$ & 58,9 & 48,9 & 48,5 & 53,5 & 45,9 & 1,3 & 0,058 & 0,406 & 0,059 \\
\hline
\end{tabular}

${ }^{1}$ Erro padrão da média. ${ }^{2} \mathrm{~L}$, Q e C: efeito de ordem linear, quadrática, cúbica, relativos à inclusão de glicerina na dieta. ${ }^{3} \mathrm{mg}$ de MS de bactérias líquido-associadas/L de líquido ruminal. ${ }^{4} \mathrm{mg}$ de $\mathrm{MO}$ de bactérias líquido-associadas/L de líquido ruminal. ${ }^{5} \mathrm{mg}$ de $\mathrm{N}$ de bactérias líquido-associadas/L de líquido ruminal.

A produção de $\mathrm{MO}(\mathrm{mg} / \mathrm{L})$ e os teores de MO (\%MS) e $\mathrm{N}(\% \mathrm{MO})$ das BLA foram alterados em função dos tempos de colheita (Tab. 3). Pode-se verificar que logo após a alimentação houve aumento no teor de $\mathrm{N}$ de $9,6 \%$ (tempo 0 h) para 10,6\% (tempo 2h). Segundo Alves et al., 2009, a proteína da dieta é catabolizada por bactérias e protozoários no rúmen em aminoácidos e amônia que são utilizados para síntese de proteína microbiana. Portanto o aumento na porcentagem de $\mathrm{N}$ após a alimentação provavelmente representa síntese de material celular. Também foi verificada redução no teor de MO das BLA após alimentação, sendo o menor valor encontrado duas horas após alimentação $(56,0 \%)$.

Tabela 3. Produção e composição de bactérias líquido-associadas do rúmen de bovinos em função dos tempos de colheita

\begin{tabular}{|c|c|c|c|c|c|c|c|c|}
\hline \multirow{2}{*}{ Item } & \multicolumn{4}{|c|}{ Tempo de colheita (h) } & \multirow[b]{2}{*}{$\mathrm{EPM}^{1}$} & \multicolumn{3}{|c|}{ Valores de $\mathrm{P}^{2}$} \\
\hline & 0 & 2 & 5 & 8 & & $\mathrm{~L}$ & $\mathrm{Q}$ & $\mathrm{C}$ \\
\hline \multicolumn{9}{|c|}{ Matéria seca } \\
\hline $\mathrm{mg} / \mathrm{L}^{3}$ & 973,7 & $\begin{array}{l}886,1 \\
\text { Matér }\end{array}$ & $\begin{array}{l}866,7 \\
\text { rgânica }\end{array}$ & 861,2 & 24,4 & 0,077 & 0,293 & 0,606 \\
\hline$\% \mathrm{MS}$ & 59,7 & 56,0 & 56,1 & 56,1 & 0,5 & 0,007 & 0,022 & 0,120 \\
\hline $\mathrm{mg} / \mathrm{L}^{4}$ & 581,9 & 498,2 & 488,7 & 491,7 & 16,3 & 0,041 & 0,109 & 0,414 \\
\hline \multicolumn{9}{|c|}{ Nitrogênio } \\
\hline$\% \mathrm{MO}$ & 9,6 & 10,6 & 10,2 & 10,3 & 0,1 & 0,186 & 0,051 & 0,018 \\
\hline $\mathrm{mg} / \mathrm{L}^{5}$ & 54,5 & 51,1 & 48,9 & 49,9 & 1,3 & 0,205 & 0,252 & 0,989 \\
\hline
\end{tabular}

${ }^{1}$ Erro padrão da média. ${ }^{2} \mathrm{~L}$, Q e C: efeito de ordem linear, quadrática e cúbica, relativos aos tempos de colheita. ${ }^{3} \mathrm{mg}$ de MS de bactérias líquido-associadas/L de líquido ruminal. ${ }^{4} \mathrm{mg}$ de $\mathrm{MO}$ de bactérias líquido-associadas/L de líquido ruminal. ${ }^{5} \mathrm{mg}$ de $\mathrm{N}$ de bactérias líquido-associadas/L de líquido ruminal.

Houve redução linear na produção de MS e N $(\mathrm{mg} / \mathrm{L})$ dos protozoários líquido-associados (Tab. 4) com o aumento na concentração de glicerina na dieta $(\mathrm{P}<0,05)$. $\mathrm{O}$ tratamento sem adição de glicerina foi $27,8 \%$ e $36,4 \%$ superior em relação ao tratamento com $20 \%$ de glicerina, respectivamente, para a produção de MS e N. A inclusão de glicerina não afetou $(\mathrm{P}>0,05)$ os teores de $\mathrm{N}(\% \mathrm{MO})$ e $\mathrm{MO}(\% \mathrm{MS})$ dos PLA nem a produção de $\mathrm{MO}(\mathrm{mg} / \mathrm{L})$.
A composição química média dos protozoários obtida por Martin et al. (1994) para MO e N foram, respectivamente, 89,5 e 5,1\%, e Ezequiel et al. (2002) encontraram 75,2 e 4,9\% para $\mathrm{MO}$ e $\mathrm{N}$, respectivamente. Neste trabalho os protozoários apresentaram em média $47,3 \%$ de MO e 7,2\% de N. Observa-se que os valores de MO foram inferiores aos obtidos nesses trabalhos citados, e que os valores de $\mathrm{N}$ estiveram acima. Isso pode ser explicado pelas diferenças entre as dietas avaliadas e a presença de solução salina. 
A utilização de glicerina...

Tabela 4. Produção e composição de protozoários líquido-associados do rúmen de bovinos em função dos tratamentos

\begin{tabular}{|c|c|c|c|c|c|c|c|c|c|}
\hline \multirow{2}{*}{ Item } & \multicolumn{5}{|c|}{ Glicerina (\%) } & \multirow[b]{2}{*}{ EPM $^{1}$} & \multicolumn{3}{|c|}{ Valores de $\mathrm{P}^{2}$} \\
\hline & 0 & 5 & 10 & 15 & 20 & & $\mathrm{~L}$ & $\mathrm{Q}$ & $\mathrm{C}$ \\
\hline \multicolumn{10}{|c|}{ Matéria seca } \\
\hline $\mathrm{mg} / \mathrm{L}$ & 2199,5 & 1837,6 & 1936,8 & 1614,9 & 1586,8 & 70,1 & 0,019 & 0,590 & 0,760 \\
\hline \multicolumn{10}{|c|}{ Matéria orgânica } \\
\hline$\% \mathrm{MS}$ & 49,7 & 45,7 & 46,8 & 45,4 & 49,0 & 06 & 0,776 & 0,112 & 0,997 \\
\hline MS & & & & & & & & & \\
\hline \multicolumn{10}{|c|}{ Nitrogênio } \\
\hline$\% \mathrm{MO}$ & 7,2 & 7,4 & 7,2 & 7,1 & 7,2 & 0,1 & 0,784 & 0,837 & 0,557 \\
\hline $\mathrm{mg} / \mathrm{L}$ & 66,4 & 52,7 & 54,7 & 42,2 & 46,0 & 2,4 & 0,039 & 0,389 & 0,978 \\
\hline
\end{tabular}

${ }^{1}$ Erro padrão da média. ${ }^{2} \mathrm{~L}$, Q e C: efeito de ordem linear, quadrática e cúbica, relativos aos tempos de colheita. ${ }^{3} \mathrm{mg}$ de MS de protozoários líquido-associados/L de líquido ruminal. ${ }^{4} \mathrm{mg}$ de $\mathrm{MO}$ de protozoários líquido-associados/L de líquido ruminal. ${ }^{5} \mathrm{mg}$ de $\mathrm{N}$ de protozoários líquido-associados/L de líquido ruminal.

Em relação aos tempos de colheita (Tab. 5), observou-se significativa redução na produção de $\mathrm{MS}, \mathrm{MO}$ e $\mathrm{N}(\mathrm{mg} / \mathrm{L})$ e nos teores de MO (\%MS) e $\mathrm{N}$ (\% MO) dos protozoários, sendo que, em todos os casos, no tempo zero (antes da alimentação), os valores foram superiores aos tempos de colheita após alimentação.

Ruiz (1992) citou que a diferença de velocidade de passagem de diferentes alimentos pelo rúmen favorece a ação dos microrganismos sobre eles. Os alimentos que estão no saco ventral (fase líquida) são rapidamente fermentados, e os microrganismos que ali se encontram podem prontamente atingir o estômago verdadeiro. Já as grandes partículas de vegetais (fase sólida) permanecem por mais tempo no saco dorsal, onde os microrganismos têm crescimento lento, e pelo fato de estarem associados às partículas maiores, permanecem no rúmen por maior tempo. A utilização de glicerina na dieta causou redução no substrato sólido para os microrganismos ruminais, consequentemente houve aumento na taxa de passagem da digesta ruminal, o que pode ter favorecido a passagem das populações de protozoários para o intestino. Ou seja, o aumento na taxa de passagem foi superior à taxa de reprodução dos mesmos, levando à redução desses microrganismos no rúmen.

A inclusão de glicerina na dieta não alterou (P>0,05) a produção de MS, MO e $\mathrm{N}(\mathrm{mg} / \mathrm{kg})$ nem o percentual de MO das BSA (Tab. 6), mas foi observado incremento linear nos teores de $\mathrm{N}$ com o aumento no percentual de inclusão de glicerina na dieta.

Tabela 5. Produção e composição de protozoários líquido-associados do rúmen de bovinos em função dos tempos de colheita

\begin{tabular}{|c|c|c|c|c|c|c|c|c|}
\hline \multirow{2}{*}{ Item } & \multicolumn{4}{|c|}{ Tempo de colheita (h) } & \multirow[b]{2}{*}{$\mathrm{EPM}^{1}$} & \multicolumn{3}{|c|}{ Valores de $\mathrm{P}^{2}$} \\
\hline & 0 & 2 & 5 & 8 & & $\mathrm{~L}$ & Q & $\mathrm{C}$ \\
\hline \multicolumn{9}{|c|}{ Matéria seca } \\
\hline $\mathrm{mg} / \mathrm{L}^{3}$ & 2217,9 & 1756,2 & 1665,0 & 1701,5 & 70,1 & 0,002 & 0,008 & 0,435 \\
\hline \multicolumn{9}{|c|}{ Matéria orgânica } \\
\hline$\% \mathrm{MS}$ & 50,5 & 46,4 & 46,7 & 45,7 & 0,6 & 0,003 & 0,049 & 0,152 \\
\hline $\mathrm{mg} / \mathrm{L}^{4}$ & 942,2 & 685,1 & 651,4 & 632,9 & 32,6 & $<, 0001$ & 0,0003 & 0,266 \\
\hline \multicolumn{9}{|c|}{ Nitrogênio } \\
\hline$\% \mathrm{MO}$ & 7,6 & 7,1 & 7,0 & 7,2 & 0,1 & 0,153 & 0,006 & 0,660 \\
\hline $\mathrm{mg} / \mathrm{L}^{5}$ & 69,9 & 49,4 & 44,4 & 45,9 & 2,4 & $<, 0001$ & 0,0003 & 0,256 \\
\hline
\end{tabular}

${ }^{1}$ Erro padrão da média. ${ }^{2} \mathrm{~L}$, Q e C: efeito de ordem linear, quadrática e cúbica, relativos aos tempos de colheita. ${ }^{3} \mathrm{mg}$ de MS de protozoários líquido-associados/L de líquido ruminal. ${ }^{4} \mathrm{mg}$ de $\mathrm{MO}$ de protozoários líquido-associados/L de líquido ruminal. ${ }^{5} \mathrm{mg}$ de $\mathrm{N}$ de protozoários líquido-associados/L de líquido ruminal. 
Tabela 6. Produção e composição de bactérias sólido-aderidas do rúmen de bovinos em função dos tratamentos

\begin{tabular}{|c|c|c|c|c|c|c|c|c|c|}
\hline \multirow{2}{*}{ Item } & \multicolumn{5}{|c|}{ Glicerina (\%) } & \multirow[b]{2}{*}{$\mathrm{EPM}^{1}$} & \multicolumn{3}{|c|}{ Valores de $\mathrm{P}^{2}$} \\
\hline & 0 & 5 & 10 & 15 & 20 & & $\mathrm{~L}$ & $\mathrm{Q}$ & $\mathrm{C}$ \\
\hline \multicolumn{10}{|c|}{ Matéria seca } \\
\hline $\mathrm{mg} / \mathrm{kg}^{3}$ & 4101,6 & 3932,1 & 3865,2 & 3775,1 & 3846,2 & 55,6 & 0,052 & 0,359 & 0,962 \\
\hline \multicolumn{10}{|c|}{ Matéria orgânica } \\
\hline$\% \mathrm{MS}$ & 63,0 & 64,2 & 62,4 & 62,7 & 62,7 & 0,3 & 0,279 & 0,917 & 0,191 \\
\hline $\mathrm{mg} / \mathrm{kg}^{4}$ & 2591,6 & 2524,8 & 2418,2 & 2368,9 & 2412,0 & 40,8 & 0,061 & 0,367 & 0,606 \\
\hline \multicolumn{10}{|c|}{ Nitrogênio } \\
\hline$\% \mathrm{MO}$ & 10,8 & 10,7 & 11,3 & 11,4 & 11,3 & 0,2 & 0,037 & 0,700 & 0,233 \\
\hline $\mathrm{mg} / \mathrm{kg}^{5}$ & 302,3 & 290,3 & 295,0 & 289,3 & 294,3 & 4,4 & 0,525 & 0,457 & 0,813 \\
\hline
\end{tabular}

${ }^{1}$ Erro padrão da média. ${ }^{2} \mathrm{~L}$, Q e C: efeito de ordem linear, quadrática e cúbica, relativos à inclusão de glicerina na dieta. ${ }^{3} \mathrm{mg}$ de MS de bactérias sólido-aderidas $/ \mathrm{kg}$ de conteúdo ruminal. ${ }^{4} \mathrm{mg}$ de $\mathrm{MO}$ de bactérias sólido-aderidas $/ \mathrm{kg}$ de conteúdo ruminal. ${ }^{5} \mathrm{mg}$ de $\mathrm{N}$ de bactérias sólido-aderidas $/ \mathrm{kg}$ de conteúdo ruminal.

A média da quantidade de MS em $\mathrm{mg} / \mathrm{kg}$ de conteúdo ruminal das BSA foi superior quando comparada com a dos demais microrganismos, sendo os valores médios de $3.131,0 \mathrm{mg} / \mathrm{kg}$; $896,9 \mathrm{mg} / \mathrm{L}$ e $1.835,1 \mathrm{mg} / \mathrm{L}$, respectivamente, para BSA, BLA e PLA. Isso pode evidenciar que, com o passar do tempo, as bactérias se aderem à fase sólida ou para se reproduzir ou para garantir o substrato (Ezequiel et al., 2002).

As produções de $\mathrm{MS}, \mathrm{MO}$ e $\mathrm{N}$ das BSA não foram influenciadas pelo tempo de colheita (Tab. 7). Já os teores de MO e $\mathrm{N}$ foram influenciados $(\mathrm{P}<0,05)$ com redução no teor de MO e incremento de $\mathrm{N}$ após alimentação, comportamento semelhante ao das bactérias associadas ao líquido. $\mathrm{O}$ incremento no teor de $\mathrm{N}$ está de acordo com o aumento na síntese de material celular após a ingestão de nutrientes.

O balanço de carboidratos estruturais e não estruturais na dieta é importante para a otimização da fermentação ruminal. Segundo Abo El-Nor et al. (2010), a redução da disponibilidade de amido e açúcares no rúmen, causada pela substituição do milho pela glicerina nas dietas, pode reduzir a população de bactérias fermentadoras de carboidratos não fibrosos e protozoários; além disso, a glicerina pode interferir na adesão de bactérias fibrolíticas às partículas de alimento, tornando os nutrientes menos acessíveis para os microrganismos ruminais.

Tabela 7. Produção e composição de bactérias sólido-aderidas do rúmen de bovinos em função dos tempos de colheita

\begin{tabular}{|c|c|c|c|c|c|c|c|c|}
\hline \multirow{2}{*}{ Item } & \multicolumn{4}{|c|}{ Tempo de colheita (h) } & \multirow[b]{2}{*}{$\mathrm{EPM}^{1}$} & \multicolumn{3}{|c|}{ Valores de $\mathrm{P}^{2}$} \\
\hline & 0 & 2 & 5 & 8 & & $\mathrm{~L}$ & Q & $\mathrm{C}$ \\
\hline \multicolumn{9}{|c|}{ Matéria seca } \\
\hline $\mathrm{mg} / \mathrm{kg}^{3}$ & 4091,3 & $\begin{array}{r}3787,6 \\
\text { Matéri }\end{array}$ & $\begin{array}{l}3861,3 \\
\text { gânica }\end{array}$ & 3875,9 & 55,6 & 0,155 & 0,151 & 0,163 \\
\hline$\% \mathrm{MS}$ & 64,0 & 63,1 & 62,9 & 62,0 & 0,3 & 0,015 & 0,937 & 0,500 \\
\hline $\mathrm{mg} / \mathrm{kg}^{4}$ & 2623,3 & 2388,9 & 2435,0 & 2405,1 & 40,8 & 0,084 & 0,164 & 0,161 \\
\hline \multicolumn{9}{|c|}{ Nitrogênio } \\
\hline$\% \mathrm{MO}$ & 10,5 & 10,8 & 11,4 & 11,7 & 0,2 & 0,026 & 0,697 & 0,616 \\
\hline $\mathrm{mg} / \mathrm{kg}^{5}$ & 306,7 & 285,9 & 291,2 & 293,0 & 4,4 & 0,360 & 0,147 & 0,251 \\
\hline
\end{tabular}

${ }^{1}$ Erro padrão da média. ${ }^{2} \mathrm{~L}$, Q e C: efeito de ordem linear, quadrática e cúbica, relativos aos tempos de colheita. ${ }^{3} \mathrm{mg}$ de MS de bactérias sólido-aderidas $/ \mathrm{kg}$ de conteúdo ruminal. ${ }^{4} \mathrm{mg}$ de $\mathrm{MO}$ de bactérias sólido-aderidas $/ \mathrm{kg}$ de conteúdo ruminal. ${ }^{5} \mathrm{mg}$ de $\mathrm{N}$ de bactérias sólido-aderidas $/ \mathrm{kg}$ de conteúdo ruminal.

$\mathrm{Na}$ literatura são descritas grandes variações na composição química dos microrganismos ruminais. Essas variações, provavelmente, são atribuídas às diferenças entre as técnicas utilizadas para isolar os microrganismos e/ou medir sua composição, além de diferença entre espécies de microrganismos relacionados ao perfil da dieta. Diversos fatores afetam a 
composição das células microbianas; entre eles, o tipo de microrganismos, a fase de crescimento e a disponibilidade de nutrientes.

Os resultados obtidos neste estudo apontam que a utilização de até $20 \%$ de glicerina na matéria seca da dieta causou redução nas quantidades de matéria seca das bactérias e protozoários associados à fase líquida sem, porém, afetar as bactérias aderidas ao sólido. O mecanismo de ação da glicerina sobre as populações de bactérias e protozoários ainda não está claro. $\mathrm{O}$ fato de as bactérias aderidas ao sólido não terem sofrido influência indica que a glicerina não afetou a adesão das bacterias às particulas fibrosas, porém a velocidade de passagem da digesta ruminal provavelmente foi aumentada, implicando redução da população na fase líquida. Essa hipótese dá suporte aos resultados obtidos em pesquisas preliminares em que houve redução na digestibilidade da fibra com o aumento da concentração de glicerina na dieta (Roger et al., 1992; Paggi et al., 2004; Abo El-Nor et al., 2010). Isso porque, se o tempo de permanência das particulas alimentares no rúmen diminuiu, consequentemente o tempo de ação dos microrganismos responsáveis pela degradação da fibra, que possuem crescimento mais lento, reduziu, resultando em diminuição na digestibilidade dessa fração. Nesse contexto, sugere-se que os efeitos da glicerina sobre os microrganismos ruminais e as consequências sobre a digestibilidade da fibra sejam mais estudados.

\section{CONCLUSÕES}

O aumento da concentração de glicerina na dieta proporcionou redução na produção de matéria seca e composição em matéria orgânica e nitrogênio das bactérias e protozoários associados ao líquido ruminal, porém não influenciou a produção nem a composição das bactérias aderidas à fase sólida do rúmen.

\section{AGRADECIMENTOS}

À Caramuru Alimentos Ltda. pelo fornecimento de parte dos ingredientes utilizados neste experimento.

\section{REFERÊNCIAS}

ABO EL-NOR, S.A.; ABUGHAZALEH, A.A.; POTU, R.B. et al. Effects of differing levels of glycerol on rumen fermentation and bacteria. Anim. Feed Sci. Technol., v.162, p.99-105, 2010.

AGÊNCIA Nacional Do Petróleo, Gás Natural E Biocombustíveis - ANP. Disponível em: <http://www.anp.gov.br/biocombustiveis/biodies el.asp>. Acessado em: 3 ago. 2012.

ALVES, T.C.; FRANZOLIN, R.; RODRIGUES, P.H.M. et al. Efeitos de dietas com níveis crescentes de milho no metabolismo ruminal de energia e proteína em bubalinos.

Rev. Bras. Zootec., v.38, p.2001-2006, 2009.

COLEMAN, G.S. Rumen entodinomorph protozoa. In:TAYLOR, A.E.R.; BAKER, J.R. (Eds.) Methods of Cultivating Parasites In Vitro. Londres: Academic Press, 1978. p.39-54.

EUGÈNE, M.; ARCHIMÈDE, H; SAUVANT, D. Quantitative meta analysis on the effects of defaunation of the rumen on growth, intake and digestion in ruminants. Livest. Sci., v.85, p.8187, 2004.

EZEQUIEL, J.M.B.; MELÍCIO, S.P.L.; SANCANARI, J.B.D. et al. Quantificação das bactérias sólido-aderidas, bactérias e protozoários líquido-associados do rúmen de bovinos jovens alimentados com amireia. Rev. Bras. Zootec., v.31, p.707-715, 2002.

GOMES, M.A.B.; MORAES, G.V.; MATAVELI, M. et al. Performance and carcass characteristics of lambs fed on diets supplemented with glycerin from biodiesel production. Rev. Bras. Zootec., v.40, p.2211-2219, 2011.

GUNN, P.J.; NEARY, M.K.; LEMENAGER, R.P. et al. Effects of crude glycerin on performance and carcass characteristics of finishing wether lambs. J. Anim. Sci., v.88, p.1771-1776, 2010.

HOMEM JUNIOR, A.C.; EZEQUIEL, J.M.B.; FÁVARO, V.R. et al. Fermentação ruminal de ovinos alimentados com alto concentrado e grãos de girassol ou gordura protegida. Arq. Bras. Med. Vet. Zootec., v.62, p.144-153, 2010.

KREHBIEL, C.R. Ruminal and physiological metabolism of glycerin. J. Anim. Sci., v.86, p.392, 2008. 
LEE, S.Y.; LEE, S.M.; CHO, Y.B. et al. Glycerol as a feed supplement for ruminants: in vitro fermentation characteristics and methane production. Anim. Feed Sci. Technol., v.166-167, p.269-274, 2011.

MACH, N.; BACH, A.; DEVANT, M. Effects of crude glycerin supplementation on performance and meat quality of Holstein bulls fed highconcentration diets. J. Anim. Sci., v.87, p.632638, 2009

MARTIN, C.; WILLIANS, A.G.; MICHALETDOREAU, B. Isolation and characteristics of the protozoal and bacterial fractions from bovine ruminal contents. J. Anim. Sci., v.72, p.29622968, 1994.

MENDES, A.R.; EZEQUIEL, J.M.B.; GALATI, R.L. et al. Cinética digestiva e eficiência de síntese de proteína microbiana em novilhos alimentados com farelo de girassol e diferentes fontes energéticas. Rev. Bras. Zootec., v.35, p.264-274, 2006.

NATIONAL Research Council - NRC. NUTRIENT requirement of beef cattle. 7.ed. Washington: National Academy Press, 1996. 242 p.
OFFICIAL methods of analysis, 16.ed. Arlington, VA: AOAC, 1995. 1025p.

PAGGI, R.A.; FAY, J.P.; FAVERIN, C. In vitro ruminal digestibility of oat hay and cellulolytic activity in the presence of increasing concentrations of short-chain acids and glycerol. J. Agric. Sci. v.142, p.89-96, 2004.

PARSONS, G.L.; SHELOR, M.K.; DROUILLARD, J.S. Performance and carcass traits of finishing heifers fed crude glycerin. $J$. Anim. Sci., v.87, p.653-657, 2009.

PYATT, N.A.; DOANE, P.H.; CECAVA, M.J. Effect of crude glycerin in finishing cattle diets. J. Anim. Sci., v.85, p.412, 2007.

ROGER, V.; FONTY, G.; ANDRE, C.; GOUET, $P$. Effects of glycerol on the growth, adhesion and cellulolytic activity of rumen cellulolytic bacteria and anaerobic fungi. Curr. Microbiol. v.25, p.197-201, 1992.

RUIZ, R.L. Microbiologia zootécnica. São Paulo: Roca, 1992. 314p.

STATISTICAL Analysis System. SAS. SAS user's guide: statistics. 5.ed. Cary, 2003. 846p. 